\title{
Sasanquasaponin from Camellia oleifera Abel. induces apoptosis via Bcl-2, Bax and caspase-3 activation in HepG2 cells
}

\author{
JIANWEI ZENG ${ }^{1,2}$, SHIQIANG CHEN ${ }^{3}, \mathrm{NA} \mathrm{LI}^{3}$, LIANG CHEN ${ }^{3}$, \\ JIAOSU $\mathrm{SU}^{3}$, GUANGJUN NIU ${ }^{3}$, $\mathrm{SI} \mathrm{ZHU}^{3}$ and YICHI LIANG ${ }^{3}$ \\ ${ }^{1}$ Academy of Integrative Medicine; ${ }^{2}$ Fujian Key Laboratory of Integrative Medicine on Geriatrics; \\ ${ }^{3}$ College of Pharmacy, Fujian University of Traditional Chinese Medicine, Fuzhou, Fujian 350122, P.R. China
}

Received April 2, 2014; Accepted March 12, 2015

DOI: $10.3892 / \mathrm{mmr} .2015 .3666$

\begin{abstract}
The present study aimed to elucidate the molecular mechanisms underlying the induction of cytotoxic effects by sasanquasaponin (SQS) in HepG2 cells. Following SQS treatment, time- and dose-dependent increases in the apoptotic rate were observed. The induction of cell death by SQS mainly occurs via programmed cell death, as indicated by Annexin V-fluorescein isothiocyanate and propidium iodide staining, where up to $30 \%$ apoptotic cells were detected following $12 \mathrm{~h} \mathrm{SQS} \mathrm{treatment.} \mathrm{Reverse} \mathrm{transcription-poly-}$ merase chain reaction analysis demonstrated that SQS treatment upregulated B-cell lymphoma-2 (Bcl-2)-associated $\mathrm{x}$ protein and caspase- 3 mRNA expression and downregulated Bcl-2 mRNA expression. Greater alterations in Bax, Bcl-2 and caspase-3 expression were observed with increasing treatment duration. The decrease in Bcl-2, increase in Bax and, finally, the activation of caspase- 3 in HepG 2 cells indicated that the apoptotic process induced by SQS was irreversible. The results of the present study therefore suggested that SQS induced HepG2 cell apoptosis via the activation of mitochondrial apoptotic pathways.
\end{abstract}

\section{Introduction}

Hepatocellular carcinoma (HCC) is the fifth most common and aggressive malignancy worldwide, accounting for $>90 \%$ of all primary liver cancers and representing the third leading cause of liver cancer mortality (1). Annually, HCC is responsible for $\sim 1$ million mortalities worldwide (2). HCC is also known as adult primary liver cancer and develops from an abnormal mass of tumor nodules, metastasizing to adjoining parts of the liver and resulting in malignancy (3). An

Correspondence to: Mr. Yichi Liang, College of Pharmacy, Fujian University of Traditional Chinese Medicine, 1 Huatuo Road, Fuzhou, Fujian 350122, P.R. China

E-mail: fafulyc@126.com

Key words: sasanquasaponin, B-cell lymphoma 2, B-call lymphoma associated x, caspase-3, HepG2 cells, apoptosis increasing body of evidence has suggested that $>0.5$ million novel cases of HCC are diagnosed annually (4). Patient prognoses following surgical resection of $\mathrm{HCC}$ remain poor due to the high rate of recurrence and dearth of effective adjuvant therapies (5). Tumor recurrence occurs in $>70 \%$ of cases within five years (6), and the five-year survival rate is just $60-70 \%$. The clinical therapies currently available require extensive immunosuppressive pre-treatments, which frequently result in undesirable physiological side-effects (7). The identification of patients with a higher risk of recurrence and the development of more effective and targeted therapeutic strategies are required in order to improve patient prognoses. Therefore, the development of novel therapeutic strategies for the treatment of HCC, with fewer adverse effects, is urgently required for the improvement of clinical practices and HCC patient prognosis.

Camellia oleifera (C. oleifera) Abel. is cultivated in numerous regions throughout China (8). C. oleifera seeds are used in the production of oil. Sasanquasaponin (SQS) is a biologically active ingredient, which may be extracted from C. oleifera Abel. SQS has numerous pharmacological properties, including anti-inflammatory, anti-hyperlipidemic and anti-effusive effects (9). Studies have revealed that SQS is able to induce apoptosis in human leukemia Jurkat cells and HepG2 hepatoma cells $(10,11)$. The present study therefore aimed to determine whether SQS was able to induce cell cycle arrest and apoptosis in the HepG2 HCC cell line, and investigate the potential mechanisms underlying these effects.

\section{Materials and methods}

Materials and reagents. RPMI-1640, fetal bovine serum (FBS), penicillin-streptomycin, Trypsin-EDTA and TRIzol were obtained from Invitrogen Life Technologies (Carlsbad, CA, USA). SuperScript II reverse transcriptase was obtained from Promega Corp. (Madison, WI, USA). B-cell lymphoma 2 (Bcl-2), Bcl-2-associated x protein Bax and $\beta$-actin primary antibodies, as well as horseradish peroxidase-conjugated secondary antibodies were purchased from Cell Signaling Technology, Inc. (Danvers, MA, USA). 5-FU was obtained from Zhejian Wanma Pharm., Co. (Hangzhou, China). All other reagents, unless otherwise stated, were obtained from Sigma-Aldrich (St. Louis, MO, USA). 
SQS drug preparation. Enrichment experiments were performed in glass columns $(2.5 \times 60 \mathrm{~cm})$ packed with AB-8 (Shanghai Resin Factory Co., Ltd., Shanghai, China). C. olifeira was obtained from Sanming City, Fujian, China. A total of $\sim 500 \mathrm{~g}$ seeds of C. olifeira were refluxed with $70 \%$ ethanol. The extracted solution was concentrated to $500 \mathrm{ml}$ without ethanol. The ethanolic extract was adjusted to $\mathrm{pH} 5.0$, and the sample flowed through the glass column at a rate of 1.0 bed volumes $(\mathrm{BV}) / \mathrm{h}$, while $0.1 \%$ $\mathrm{NaOH}$ solution was added via the separatory funnel, in order to elute impurities and pigment. Following clarification, the sample was sequentially eluted with distilled water to neutral, and then with $90 \%$ ethanol (Sinopharm Chemical Reagent Co., Ltd., Beijing, China) solution (containing 1\% NaOH; Sinopharm Chemical Reagent Co., Ltd.) at a constant flow rate of $2.0 \mathrm{BV} / \mathrm{h}$. Each fraction was collected and evaporated to remove the ethanol using a rotary evaporator (RE52AA; Yarong Equipment Co., Shanghai, China) under reduced pressure at $55^{\circ} \mathrm{C}$. Subsequently, $500 \mathrm{ml}$ acetone (Sinopharm Chemical Reagent Co., Ltd.) was added to the concentrated liquid and left to stand overnight, followed by centrifugation at $1,006 \mathrm{x}$ g for $30 \mathrm{~min}$. The sediment was dissolved in $70 \%$ ethanol, placed in the fridge at $4^{\circ} \mathrm{C}$ overnight, filtered and dried at $60^{\circ} \mathrm{C}$ to a constant weight $(500 \mathrm{~g})$ to produce high-purity SQS crystals (5 g) (12).

Cell culture and treatment. Immortalized HepG2 human hepatocellular carcinoma cells were obtained from the Live Cancer Institute of Zhongshan Hospital (Shanghai, China) and maintained in Dulbecco's modified Eagle's medium containing $10 \% \mathrm{FBS}$ and $1 \%$ penicillin/streptomycin solution at $37^{\circ} \mathrm{C}$ in $5 \% \mathrm{CO}_{2}$. All experiments were performed while the cells were in an exponential growth phase (13).

Cytotoxicity assay. HepG2 cells were seeded into standard 96-well culture plates at a density of $2.0 \times 10^{4}$ cells/well and cultured to $\sim 70 \%$ confluence. Cells were maintained in medium containing various concentrations $(0,10,20$ or $30 \mu \mathrm{g} / \mathrm{ml})$ of SQS and $30 \mu \mathrm{g} / \mathrm{ml} \mathrm{5-FU} \mathrm{for} 6,12$ or $24 \mathrm{~h}$ prior to the addition of $20 \mu \mathrm{l}$ MTT solution (5 mg/ml MTT) to each well and cultured for a further $4 \mathrm{~h}$. The medium was subsequently removed and $150 \mu \mathrm{l} /$ well dimethyl sulfoxide was added and incubated for $10 \mathrm{~min}$ whilst shaking gently to stop the reaction. The optical density (OD) at $570 \mathrm{~nm}$ was read using an ELISA reader (ELX800; BioTek Instruments, Inc., Winooski, VT, USA). Each independent experiment was performed in triplicate (14).

Cell apoptosis analysis. Annexin V staining (in the presence or absence of SQS) and cell scanning were conducted using an Annexin V-fluorescein isothiocyanate (FITC) detection kit (Beyotime Institute of Biotechnology, Haimen, China). The HepG2 cells were treated with $0,10,20$ or $30 \mu \mathrm{g} / \mathrm{ml} \mathrm{SQS}$ for $12 \mathrm{~h}$. To detect apoptosis, $1 \times 10^{5}$ cells were resuspended in $500 \mu \mathrm{l}$ binding buffer in the presence of $5 \mu \mathrm{l}$ Annexin V-FITC and $5 \mu \mathrm{l}$ propidium iodide and incubated at room temperature for $15 \mathrm{~min}$ in the dark. The fluorescence was measured using a FACScan flow cytometer (BD Bioscience) and the mean fluorescent intensity of triplicate samples for each SQS concentration cohort was used to ascertain the levels of Annexin V. The data were analyzed using CellQuest software version 1.0 (BD Biosciences, Franklin Lakes, NJ, USA) (15).
Cell cycle analysis. HepG2 cells were treated with 0, 10, 20 or $30 \mu \mathrm{g} / \mathrm{ml} \mathrm{SQS}$ for $12 \mathrm{~h}$. Subsequently, cells were harvested, washed with solution buffer and fixed in cold $70 \%$ ethanol overnight. A DNA content detection kit (Beyotime Institute of Biotechnology, Haimen, China) was used for cell cycle analysis. The cells were collected and suspended in $100 \mu \mathrm{l}$ solution A and incubated at room temperature for $10 \mathrm{~min}$. Analogous conditions were used upon the addition of $100 \mu \mathrm{l}$ solution B and $150 \mu 1$ solution C. Cell cycle progression was analyzed using a FACScan flow cytometer (BD Biosciences). The percentages of cells in $G_{0} / G_{1}, S$ and $G_{2} / M$ phases were determined using ModFitLT software version 3.0 (Verity Software House, Topsham, ME, USA).

Reverse transcription-polymerase chain reaction (RT-PCR) and gene expression analysis. RT-PCR was performed as described previously (16). HepG2 cells were seeded into six-well plates at a density of $1 \times 10^{5}$ cells/well in $2 \mathrm{ml}$ medium and treated with $0,10,20$ or $30 \mu \mathrm{g} / \mathrm{ml} \mathrm{SQS}$ for $12 \mathrm{~h}$. Total RNA was isolated with TRIzol, and oligo (dT)-primed RNA $(1 \mu \mathrm{g})$ was reverse-transcribed using SuperScript II reverse transcriptase (Promega Corp.) according to the manufacturer's instructions. The obtained cDNA was used to determine the mRNA expression levels of Bcl-2, Bax and caspase-3 by PCR analysis. GAPDH was used as an internal control. The primer sequences used for the amplification of Bcl-2, Bax, caspase-3 and GAPDH were as follows: Bcl-2 forward, 5'-TTCTCTCGTCGCTACCGTCGC-3' and reverse, 5'-CCT CCCCCAGTTCACCCCATC-3'; Bax forward, 5'-CTTTTT GCTACAGGGTTTCA-3' and reverse, 5'-CCATGTTGTTGT CCAGTTCAT-3'; caspase-3 forward, 5'-CAGAAGATACCA GTGGAGGCC-3' and reverse, 5'-TTCCGGTTAACACGA GTGAGG-3'; GADPH forward, 5'-CGACCACTTTGTCA AGCTCA-3' and reverse, 5'-AGGGGTCTACATGGCAA CTG-3'. All primers were synthesized by Sangon Biotech (Shanghai, China). The reaction included $1 \mu \mathrm{l}$ cDNA, $2 \mu \mathrm{l}$ 10X Taq Buffer, $1.2 \mu \mathrm{l} 25 \mathrm{mM} \mathrm{MgCl}_{2}, 0.4 \mu \mathrm{l} 10 \mathrm{mM}$ dNTP, $0.8 \mu \mathrm{l} 1 \mathrm{U} / \mu \mathrm{L}$ Taq polymerase, $1 \mu \mathrm{l}$ each primer and DEPC water upto $20 \mu \mathrm{l}$. The PCR conditions were as follows: $95^{\circ} \mathrm{C}$ for $3 \mathrm{~min}$ and 30 cycles at $95^{\circ} \mathrm{C}$ for $30 \mathrm{sec}, 56^{\circ} \mathrm{C}$ for $40 \mathrm{sec}$ and $72^{\circ} \mathrm{C}$ for $40 \mathrm{sec}$. Samples were analyzed by $1.5 \%$ agarose gel electrophoresis. The DNA bands were evaluated using a Gel Documentation system (Gel Doc 2000; Bio-Rad Laboratories, Inc., Hercules, CA, USA).

Western blot analysis. HepG2 cells were seeded in culture dishes $\left(2 \times 10^{5} /\right.$ well $)$ and treated with $0,10,20$ or $30 \mu \mathrm{g} / \mathrm{ml} \mathrm{SQS}$ for $12 \mathrm{~h}$. The cells were washed twice with phosphate-buffered saline (PBS) and lysed with lysis buffer according to the manufacturer's instructions. The protein concentration of the lysate was determined via the bicinchoninic acid assay (Pierce, Rockford, IL, USA). Samples were analyzed using 10\% SDS-PAGE (Dingguo Biotech., Fuzhou, China). Following electrophoresis, the proteins were transferred onto polyvinylidene difluoride membranes. The membranes were blocked with 5\% skimmed milk in PBS with Tween 20 (PBST; Xilong Chemical Co., Ltd., Shantou, China) for $1.5 \mathrm{~h}$ and incubated with rabbit anti-Bcl-2, anti-Bax and anti-caspase-3 antibodies (1:1,000 dilution) at $4^{\circ} \mathrm{C}$ overnight. Following three washes with PBST buffer, the membranes were incubated 


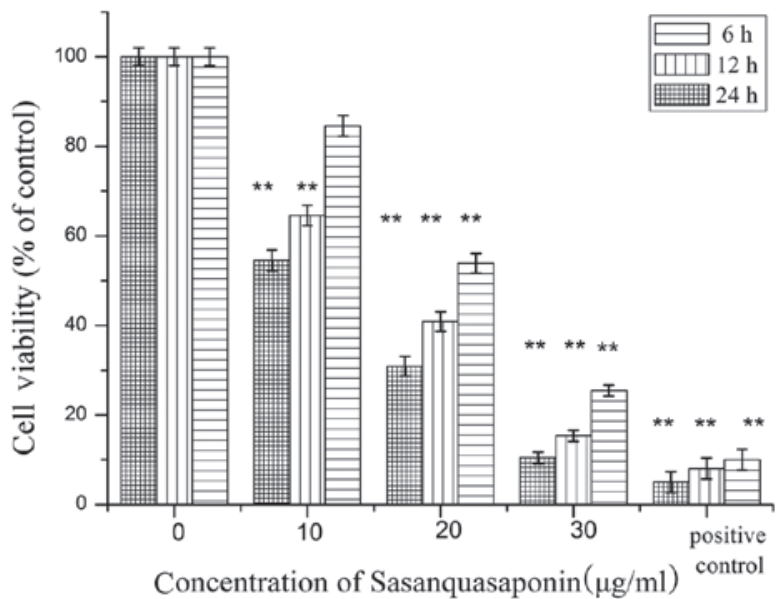

Figure 1. Determination of sasanquasaponin cytotoxicity in HepG2 cells using the MTT assay. HepG2 cells were incubated with the indicated concentrations of SQS for 6, 12 or $24 \mathrm{~h}$. For the cell death-positive control, cells were incubated with 5 -fluorouracil $(30 \mu \mathrm{g} / \mathrm{ml}) .{ }^{* *} \mathrm{P}<0.01$ compared with the respective control.
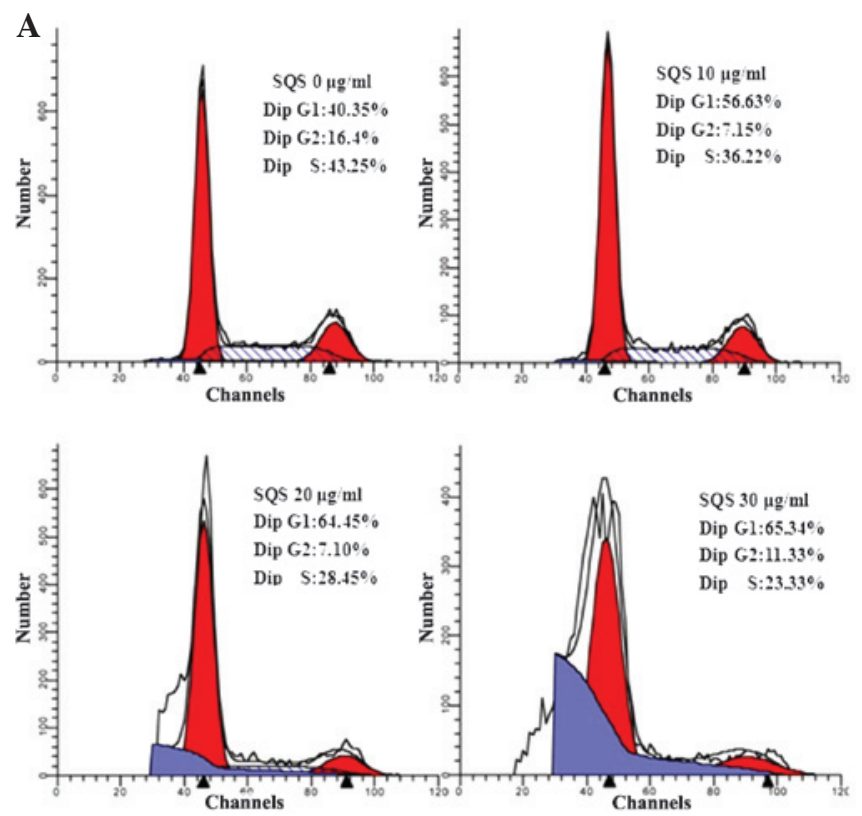

B

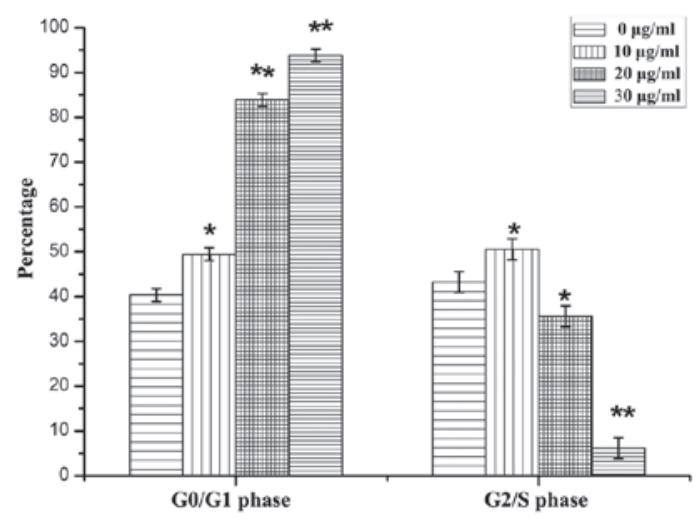

Figure 2. Effects of SQS on HepG2 cell cycle progression. (A) Cells were treated with the indicated concentrations of SQS for $24 \mathrm{~h}$, stained with propidium iodide and analyzed by fluorescence-activated cell sorting. Images are representative of three independent experiments. (B) The proportion of cells in $\mathrm{G}_{0} / \mathrm{G}_{1}$ and $\mathrm{G}_{2} / \mathrm{S}$ phase was calculated using ModfitLT software. Values are presented as the mean \pm standard deviation of three independent experiments. ${ }^{\text {"P }} \mathrm{P}<0.05$ vs. untreated cells, ${ }^{* * *} \mathrm{P}<0.01$ vs. untreated cells. SQS, sasanquasaponin.
$\mathbf{A}$
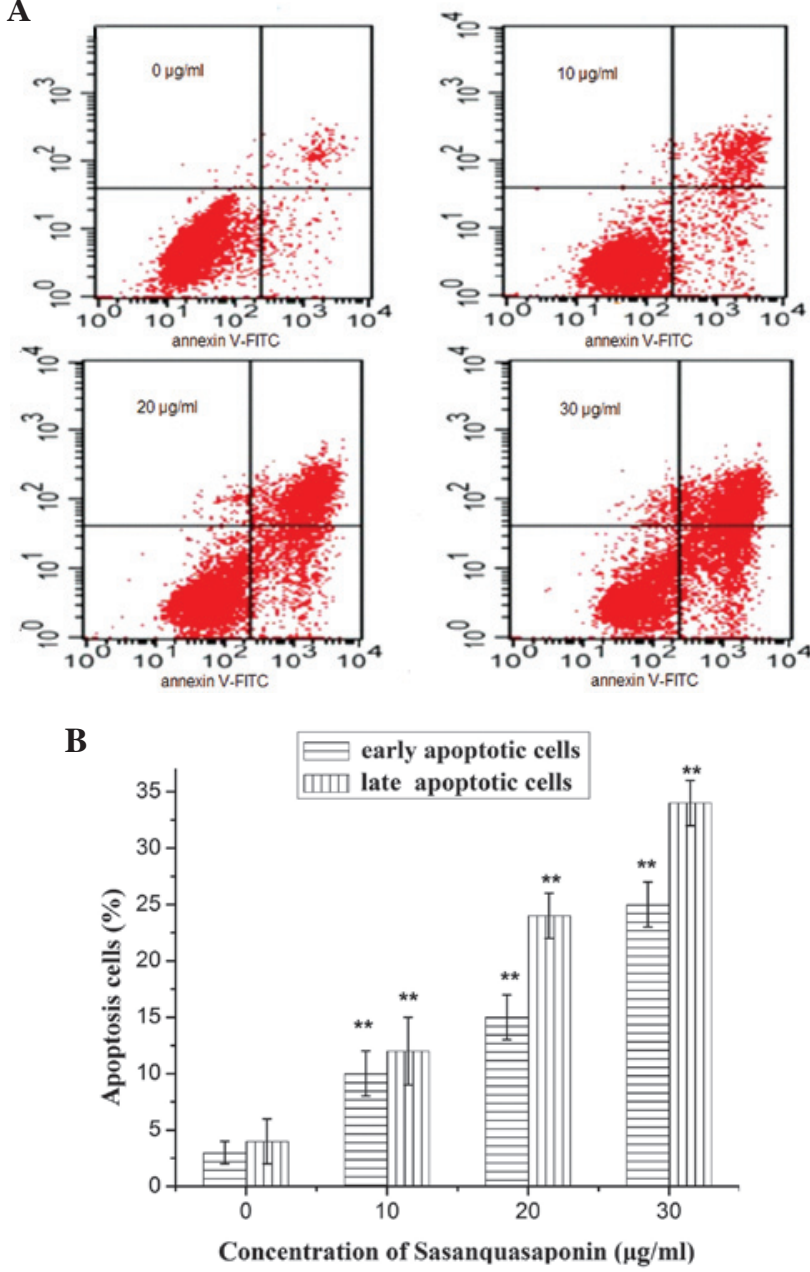

Figure 3. Induction of apoptosis in SQS-treated HepG2 hepatocelluar carcinoma cells. (A) Dot plot diagrams obtained from flow cytometric analysis of Annexin V-fluorescein isothiocyanate and propidium iodide fluorescence of cells treated with $0,10,20$ or $30 \mu \mathrm{g} / \mathrm{ml} \mathrm{SQS}$ for $12 \mathrm{~h}$. The upper and lower right quadrants were used to measure the percentage of apoptotic cells. The figure is representative of at least three independent experiments; (B) bar graph summarizing the percentage of apoptotic cells in each treatment group. Values are presented as the mean \pm standard deviation of triplicate experiments. ${ }^{* *} \mathrm{P}<0.05$ vs. untreated cells. SQS, sasanquasaponin.

with goat anti-rabbit immunoglobulin $\mathrm{G}$ conjugated with horseradish peroxidase for $2 \mathrm{~h}$ at room temperature. Following three washes with PBST, the protein bands were detected using enhanced chemiluminescence using Clarity Western Substrate (Bio-Rad, Hercules, CA, USA), according to the manufacturer's instructions and images were captured using a ChemiDoc XRS+ system (Bio-Rad). $\beta$-actin was used as the control to confirm equal loading. Densitometry index analysis of the bands was conducted using a gel imagery system (17).

Statistical analysis. Values are presented as the mean \pm standard deviation. Results were analyzed by one-way analysis of variance. When significant treatment effects were detected, Tukey-Kramer's t-test was performed to make pairwise comparisons between individual means. Statistical analysis software SPSS 19.0 (International Business Machines, Armonk, NY, USA) was used to conduct statistical analyses. $\mathrm{P}<0.05$ was considered to indicate a statistically significant difference. 
A
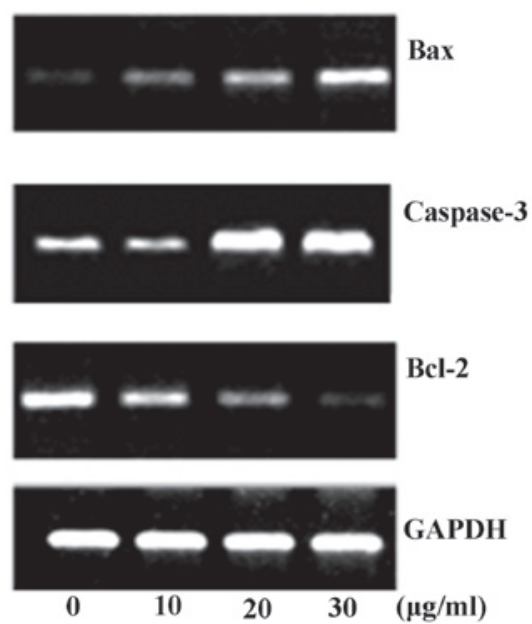

B

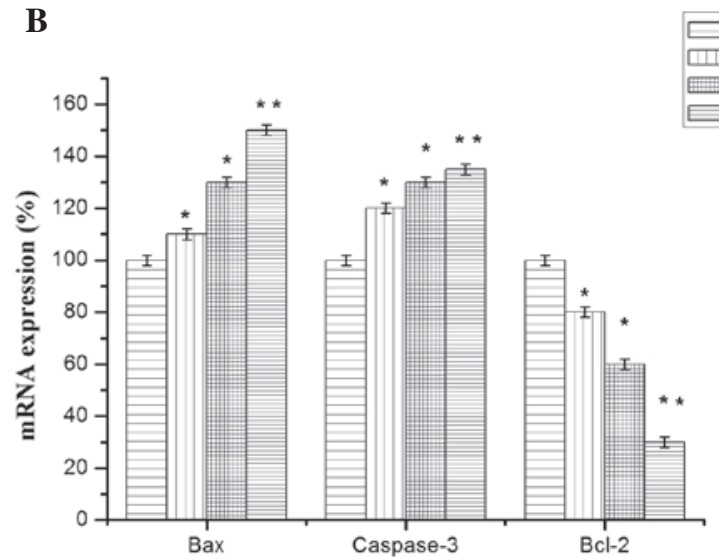

Figure 4. Effects of SQS treatment on the mRNA expression levels of Bax, Bcl-2 and caspase- 3 in HepG2 cells. Cells were treated with the indicated concentrations of SQS for $12 \mathrm{~h}$. (A) mRNA expression levels of Bax, Bcl-2 and caspase-3 in SQS-treated and untreated cells were determined by RT-PCR. GAPDH was used as an internal control. (B) Relative intensity expression obtained from the corresponding RT-PCR analyses. Values are expressed as the mean \pm standard deviation of at least three independent experiments ${ }^{*} \mathrm{P}<0.05$ and ${ }^{* *} \mathrm{P}<0.01$ vs. untreated cells. RT-PCR, reverse transcription-polymerase chain reaction; SQS, sasanquasaponin; Bcl-2, B-cell lymphoma 2; Bax, Bcl-2-associated $\mathrm{x}$ protein.

\section{Results}

SQS reduces HepG2 cell viability. The MTT assay suggested that cytotoxic effects occurred 6, 12 and $24 \mathrm{~h}$ following incubation with SQS, even at doses as low as $20 \mu \mathrm{g} / \mathrm{ml}$ SQS. As indicated in Fig. 1, the degree of cytotoxicity was directly proportional to the concentration of SQS, suggesting a dose-dependent effect. The results of the MTT test indicated that following $6 \mathrm{~h}$ of incubation with 10,20 or $30 \mu \mathrm{g} / \mathrm{ml} \mathrm{SQS}$, cell survival was reduced to $84.56,53.86$ and $25.25 \%$, respectively.

SQS alters HepG2 cell cycle progression. The cell cycle has a key function in HepG2 cells, inducing their division and duplication. In addition, the $\mathrm{G}_{1} / \mathrm{S}$-phase transition represents one of the major checkpoints used in the regulation of cell cycle progression. Once the cell cycle passes this checkpoint late in $G_{1}$ phase, progression through the cell cycle continues with little or no extracellular stimuli (18). As indicated in Fig. 2, the proportion of cells in $\mathrm{G}_{0} / \mathrm{G}_{1}$ phase following treatment
A
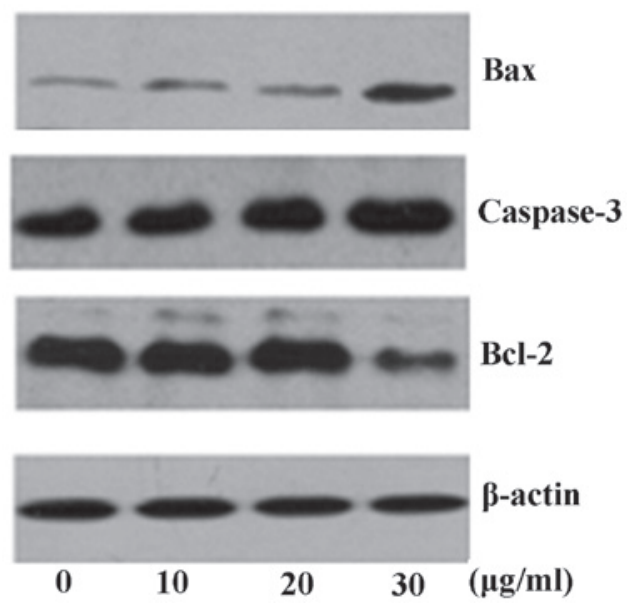

B

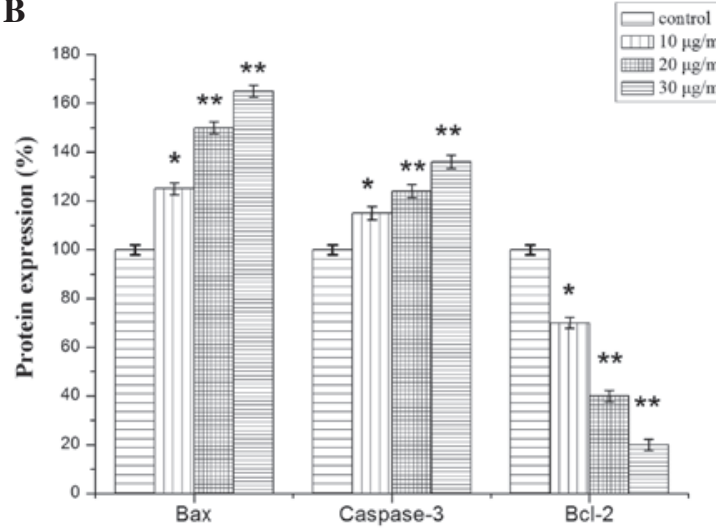

Figure 5. Effects of SQS treatment on the protein expression levels of Bax, Bcl-2 and caspase-3 in HepG2 cells. Western blot analyses of HepG2 cells treated with $0,10,20$ or $30 \mu \mathrm{g} / \mathrm{ml}$ sasanquasaponin for $12 \mathrm{~h}$. HepG2 cell extracts were obtained and subjected to SDS-PAGE and western blot analysis for caspase-3, Bax and Bcl-2. (A) Western blot representative of three independent experiments. $\beta$-actin was used to verify uniform protein loading. (B) Relative intensity expression obtained from the corresponding western blot analyses. Values are expressed as the mean \pm standard deviation of at least three independent experiments. ${ }^{*} \mathrm{P}<0.05$ and ${ }^{* *} \mathrm{P}<0.01$ vs. untreated cells. Bcl-2, B-cell lymphoma 2; Bax, Bcl-2-associated x protein.

with 10,20 or $30 \mu \mathrm{g} / \mathrm{ml} \mathrm{SQS} \mathrm{was} 56.63 \pm 1.76,64.45 \pm 1.47$ and $65.34 \pm 1.67 \%$, a significantly higher proportion than that of untreated cells $(40.35 \pm 1.33 \% ; \mathrm{P}<0.05)$. Concurrently, the percentage of cells in S phase following SQS treatment demonstrated the opposite trend. It was therefore suggested that SQS treatment may arrest cell cycle progression of HepG2 cells by inhibiting the $\mathrm{G}_{1}$ to $\mathrm{S}$ phase transition.

SQS induces apoptosis of HepG2 cells. To determine the mechanisms underlying the effects of SQS treatment on HepG2 cells, membrane alterations were analyzed by flow cytometry and double staining with Annexin V-FITC and PI. A progressive increase in the percentage of apoptotic cells was observed with increasing SQS concentration, which demonstrated the dose-dependent cytotoxicty of SQS to HepG2 cells (Fig. 3).

Expression levels of Bcl-2, Bax and caspase-3. Based on the aforementioned results, the association between the expression of apoptotic factors and SQS-induced apoptosis of HepG2 cells was investigated. The mRNA and protein expression levels of 
apoptosis-associated factors Bcl-2, Bax and caspase-3 were therefore evaluated (19). A significant reduction in Bcl-2 mRNA expression levels was observed following treatment with 10, 20 and $30 \mu \mathrm{g} / \mathrm{ml} \mathrm{SQS}$, compared with those in untreated cells (Fig. 4). Conversely, a significant increase in caspase 3 and Bax mRNA expression was observed. An analogous trend was observed in the protein expression levels of caspase-3, Bcl-2 and Bax following SQS treatment (Fig. 5).

\section{Discussion}

The results of the present study revealed that SQS inhibited human HepG2 hepatocellular carcinoma cell growth, indicated by a decrease in cell density following SQS treatment. Furthermore, the mRNA and protein expression levels of key apoptotic regulators Bax, Bcl-2 and caspase- 3 were found to be altered following SQS treatment (20).

It has previously been demonstrated that the intracellular signaling pathways influenced by SQS and its metabolites are involved in the regulation of numerous cell signaling pathways, which contribute to the activation or inhibition of various cellular processes (21). SQS influences not only the transduction of signals from the extracellular space, but also functions as a mediator and modulator of intercellular and intracellular signaling networks (22-24).

The results of the present study indicated that pre-treatment of HepG2 cells with SQS resulted in Annexin V-positive staining. These results suggested that SQS may block the signal transduction pathway required for cell survival and induce HepG2 cell apoptosis. The mRNA and protein expression levels of $\mathrm{Bcl}-2$, caspase- 3 and Bax were therefore examined. Bax is a pro-apoptotic Bcl-2 protein, which contains $\mathrm{BH} 1, \mathrm{BH} 2$ and $\mathrm{BH} 3$ domains and initiates apoptotic signaling. The expression of Bax is upregulated by the tumor suppressor protein p53, and Bax has been shown to be involved in p53-mediated apoptosis. The results of the present study demonstrated that SQS treatment increased Bax expression in HepG2 cells. Caspase-3 is encoded by the CASP3 gene and interacts with caspase- 8 and -9 . In apoptotic cells, caspase-3 activation may occur via extrinsic (death ligand) or intrinsic (mitochondrial) pathways. Of note, Bax is involved in the intrinsic pathway. Activated caspase- 3 induces caspase- 8 activation and subsequently activates Bax, which stimulates cytochrome $C$ and induces apoptosis (25). An identical signaling pathway was identified in the HepG2 cells evaluated in the present study. Caspase-3 activation was previously demonstrated to be increased following treatment of cells with SQS $(26,27)$.

SQS interacts with mitochondrial membranes and alters their permeability by opening transition pores and decreasing the mitochondrial membrane potential (28). SQS therefore induces structural changes and increases mitochondrial membrane unsaturation.

These mitochondrial alteration may influence the activity of pro- and anti-apoptotic proteins of the Bcl-2 family. It was previously demonstrated that SQS contributes to the downregulation of Bcl-2 expression, a well-known anti-apoptotic molecule, and blocks lipid peroxidation; therefore, inhibiting the induction of apoptosis (29). The results of the present study indicated that SQS suppressed Bcl-2 expression.
Based on previously published studies and the results of the present study, it was hypothesized that SQS induces human hepatocellular carcinoma cell apoptosis. The signal transduction occurs via the caspase-3 signaling pathway. Further study on this signaling pathway is required to elucidate the function of SQS in tumor invasion and survival.

\section{Acknowledgements}

The present study was supported by the Key Projects Science Foundation of Fujian province (grant no. 2011J05073) and the Natural Science Foundation of Fujian Province (grant no. 2011J05073).

\section{References}

1. Evan GI and Vousden KH: Proliferation, cell cycle and apoptosis in cancer. Nature 411: 342-348, 2001.

2. Jemal A, Bray F, Center MM, et al: Global cancer statistics. CA Cancer J Clin 61: 69-90, 2011.

3. Liu Y, Liu A, Xu Z, et al: XZH-5 inhibits STAT3 phosphorylation and causes apoptosis in human hepatocellular carcinoma cells. Apoptosis 3: 502-510, 2011.

4. Ercolani G, Grazi GL, Ravaioli M, et al: Liver resection for hepatocellular carcinoma on cirrhosis: Univariate and multivariate analysis of risk factors for intrahepatic recurrence. Ann Surg 237: 536-543, 2003.

5. Zhong W, Peng J, He H, et al: Ki-67 and PCNA expression in prostate cancer and benign prostatic hyperplasia. Clin Invest Med 31: E8-E15, 2008.

6. Longley DB, Allen WL and Johnston PG: Drug resistance, predictive markers and pharmacogenomics in colorectal cancer. Biochim Biophys Acta 1766: 184-196, 2006.

7. Pizova K, Tomankova K, Daskova A, et al: Photodynamic therapy for enhancing antitumour immunity. Biomed Pap Med Fac Univ Palacky Olomouc Czech Repub 156: 93-102, 2012.

8. Zhang XF, Han YY, Bao GH, et al: A new saponin from tea seed pomace (Camellia oleifera Abel.) and its protective effect on PC12 cells. Molecules 17: 11721-11728, 2012.

9. Sagesaka YM, Uemura T, Suzuki Y, et al: Antimicrobial and anti-inflammatory actions of tea-leaf saponin. Yakugaku Zasshi 116: 238-243, 1996 (In Japanese).

10. Ma LY, Li L, Jiang Y, et al: Study on Youchasaponin-induced apoptosis of HepG2 cells through the endoplasmic reticulum stress. Chin Pharmacol Bull 27: 1523-1527, 2011.

11. Ma LY, Li L, Jiang Y, et al: Youchasaponin induces apoptosis of human leukemia Jurkat cells in vitro and its possible mechanism. Tumor 31: 1072-1076, 2011.

12. Yang JJ, Hsu HY, Ho YH and Lin CC: Comparative study on the immunocompetent activity of three different kinds of Peh-Hue-Juwa-Chi-Cao, Hedyotis diffusa, H. corymbosa and Mollugo pentaphylla after sublethal whole body X-irradiation. Phytother Res 11: 428-432, 1997.

13. Lin JM, Wei LH, Xu W, et al: Effect of Hedyotis diffusa Willd extract on tumor angiogenesis. Mol Med Rep 4: 1283-1288, 2011.

14. Boos G and Stopper H: Genotoxicity of several clinically used topoisomerase II inhibitors. Toxicol Lett 116: 7-16, 2000.

15. Kelloff GJ: Perspectives on cancer chemoprevention research and drug development. Adv Cancer Res 78: 199-334, 2000.

16. Singh S, Johnson J and Chellappan S: Small molecule regulators of Rb-E2F pathway as modulators of transcription. Biochim Biophys Acta 1799: 788-794, 2010.

17. Shortkroff S and Yates KE: Alteration of matrix glycosaminoglycans diminishes articular chondrocytes' response to a canonical Wnt signal. Osteoarthritis Cartilage 15: 147-154, 2007.

18. Chen Y, Robles AI, Martinez LA, et al: Expression of G1 cyclins, cyclin-dependent kinases, and cyclin-dependent kinase inhibitors in androgen-induced prostate proliferation in castrated rats. Cell Growth Differ 7: 1571-1578, 1996.

19. Graña X and Reddy EP: Cell cycle control in mammalian cells: role of cyclins, cyclin dependent kinases (CDKs), growth suppressor genes and cyclin-dependent kinase inhibitors (CKIs). Oncogene 11: 211-219, 1995. 
20. Chen HP, He M, Mei ZJ, et al: Sasanquasaponin up-regulates anion exchanger 3 expression and elicits cardioprotection via NO/RAS/ERK1/2 pathway. Can J Physiol Pharmacol 90: 873-880, 2012

21. Aszodi A, Hunziker EB, Brakebusch C and Fässler R: Betal integrins regulate chondrocyte rotation, G1 progression, and cytokinesis. Genes Dev 17: 2465-2479, 2003.

22. Li R, Zhao HR and Lin YM: Anti-tumor effect and protective effect on chemotherapeutic damage of water soluble extracts from Hedyotis diffusa. J Chin Pharm Sci 11: 54-58, 2002.

23. Lin J, Chen Y, Wei L, et al: Hedyotis diffusa Willd extract induces apoptosis via activation of the mitochondrion-dependent pathway in human colon carcinoma cells. Int J Oncol 37: 1331-1338, 2010.

24. Handayani T, Sakinah S, Nallappan M, et al: Regulation of p53-, Bcl-2 and caspase-dependent signaling pathway in xanthorrhizol-induced apoptosis of HepG2 hepatoma cells. Anticancer Res 27: 965-971, 2007.
25. Lee HP, Chen YL, Shen HC, Lo WH and Hu YC: Baculovirus transduction of rat articular chondrocytes: roles of cell cycle. J Gene Med 9: 33-43, 2007.

26. Löwenheim $\mathrm{H}$, Reichl J, Winter $\mathrm{H}$, et al: In vitro expansion of human nasoseptal chondrocytes reveals distinct expression profiles of G1 cell cycle inhibitors for replicative, quiescent, and senescent culture stages. Tissue Eng 11: 64-75, 2005.

27. Chen L, Chen J and Xu H: Sasanquasaponin from Camellia oleifera Abel. induces cell cycle arrest and apoptosis in human breast cancer MCF-7 cells. Fitoterapia 84: 123-129, 2013.

28. Harper JW, Elledge SJ, Keyomarsi K, et al: Inhibition of cyclin-dependent kinases by p21. Mol Biol Cell 6: 387-400, 1995.

29. Hwang SG, Song SM, Kim JR, et al: Regulation of type II collagen expression by cyclin-dependent kinase 6 , cyclin D1, and p21 in articular chondrocytes. IUBMB Life 59: 90-98, 2007. 